\title{
Espacio y violencia en Persona de José Carlos Agüero
}

\section{(1) María Emilia Artigas}

CONICET, Instituto de Humanidades y Ciencias Sociales / Universidad Nacional de Mar del Plata, Argentina

\begin{abstract}
Resumen
El conflicto interno peruano (1980-2000) finalizó hace más de dos décadas; no obstante, perduran en la sociedad actual secuelas que víctimas y agentes activos involucrados en la guerra han plasmado en el discurso literario. En este artículo se estudiará el modo de configuración discursiva del espacio en relación con la violencia en Persona (2017) del autor peruano José Carlos Agüero, quien es hijo de senderistas asesinados por las fuerzas armadas peruanas, historiador, poeta y activista de Derechos Humanos. En sus textos pueden observarse trazos espaciales que señalan no solo los lugares donde vivieron, lucharon y murieron sus padres sino también una zona donde se construye su identidad desde la escritura. Se trabajarán las dimensiones de la memoria (Todorov, 2000; LaCapra, 2001; Jelin, 2002) para problematizar el espacio de constitución de la subjetividad de las víctimas durante el postconflicto.
\end{abstract}

PALABRAS CLAVE: Literatura peruana, violencia, memoria, Sendero Luminoso, José Carlos Agüero

\section{Andean Space and Violence in Persona, by José Carlos Agüero}

\begin{abstract}
Although Peru's internal conflict (1980-2000) concluded some two decades ago, cultural and ideological sequels remain, as can be observed in different samples of literary discourse by victims and agents involved in the war. In this article, we study in Persona (2017), by Peruvian writer José Carlos Agüero, the discursive configuration of Andean space as it concerns violence. The author is son of "senderistas" killed by Peruvian Army, historian, poet, and a Human Rights activist. In his texts, spatial strokes indicate not only the places where his parents lived, fought and died, but also the place where his identity is built through writing. The dimensions of memory (Todorov, 2000; LaCapra, 2001; Jelin, 2002) are reviewed in order to problematize the space in which victims' subjectivity is constructed during the post-conflict.
\end{abstract}


KEYWORDS: Peruvian Literature, violence, memory, Sendero Luminoso, José Carlos Agüero

\section{Espaço andino e violência em Persona, por José Carlos Agüero}

\section{Resumo}

O conflito interno peruano (1980-2000) terminou há mais de duas décadas; no entanto, perduram no interior da sociedade sequelas culturais e ideológicas que as vítimas e os participantes envolvidos na guerra plasmaram no discurso literário. Neste artigo, será analisado o modo de configuração discursiva do espaço andino em relação à violência em Persona (2017), de José Carlos Agüero, historiador peruano, poeta e ativista dos direitos humanos, filho de "senderistas" desaparecidos. Em seus textos é possível identificar certos traços que indicam não apenas os lugares nos quais seus pais moraram, lutaram e morreram, mas também um espaço no qual sua identidade é construída a partir da escrita. Através da análise deste livro, serão trabalhadas as dimensões da memória para problematizar o espaço na constituição da subjetividade das vítimas durante o pós-conflito (Todorov, 2000; LaCapra, 2001; Jelin, 2002).

PALAVRAS CHAVE: Literatura peruana, Violência, Memória, Sendero Luminoso, José Carlos Agüero

El abordaje del entramado de la memoria desde el discurso literario brinda operaciones de exploración que permiten conocer/reconstruir el pasado traumático. Ofrecerá entonces la potencialidad para captar las interferencias entre lo dicho y lo silenciado en textos en los que no es lo mismo lo narrado que lo narrable. Dentro de los relatos sobre el conflicto armado peruano (1980-2000), se distinguen aquellos que muestran un afán por dar cuenta de un pasado colectivo desde las inflexiones vitales individuales. La sociedad peruana postconflicto evidencia huellas visibles en los ámbitos económico y político, cultural e ideológico, por lo cual, muchas de las víctimas y agentes activos involucrados en la guerra encuentran en la literatura un escenario posible para dar a conocer sus vivencias y experiencias traumáticas silenciadas por los aparatos estatales. En este artículo se estudiará el modo de configuración discursiva del espacio andino en relación con la violencia en Persona (2017), del autor peruano José Carlos Agüero, quien es hijo de senderistas asesinados por las fuerzas armadas del ejército peruano, historiador, poeta y activista de Derechos Humanos. En su escritura pueden observarse trazos espaciales que señalan no solo los lugares relacionados con las acciones políticas de sus padres, sino también una zona donde se construye su identidad como víctima y observador de la violencia del pasado. Su lectura invita a revisar las dimensiones de la memoria, para problematizar el espacio de constitución de la subjetividad de las víctimas durante el postconflicto.

Los padres de José Carlos Agüero murieron en situaciones extraoficiales durante el conflicto armado: su madre (Silvia Solórzano) fue acribillada a balazos por las fuerzas policiales en una playa de Chorrillos, y su padre (José Manuel Agüero) falleció como preso político en el Penal de El Frontón. Este escritor, un intelectual diplomado en Derechos Humanos, miembro del Taller de Estudios de Memoria, se desempeñó como activista e investigador de la violencia política y de la memoria histórica. De ahí que sus trabajos literarios autobiográficos estén interceptados inexorablemente por su condición de víctima del conflicto armado como hijo de agentes activos de la guerra. 
En este trabajo se estudiarán las operaciones de escritura de esta voz poética que articula su autobiografía traumática con sus investigaciones de archivo. La noción de víctima funciona como un concepto recurrente con el cual se identifica el sujeto porque encuentra en él un dispositivo semántico que opera en contra del olvido. Así, la forma de nombrar(se) como activista, investigador y víctima propone un juego de tensión entre realidad y ficción en tanto todo dicho es suficiente para demostrar que los discursos orientados a revelar los hechos, es decir, los textos con un afán testimonial, se ponen en juego en niveles que exceden las aseveraciones relativas a los sucesos (LaCapra, 2005: 37). Así, el lenguaje expresa las vivencias individuales y colectivas, de tal modo que la escritura deja de informar lo meramente documental.

\section{Una escritura autobiográfica en la escena postconflicto}

En línea con la observación de LaCapra debe subrayarse uno de los rasgos significativos del autor: su participación en el volumen colaborativo Memoria para los ausentes, del año 2001, el primer libro publicado sobre los desaparecidos que trata el tema de la violencia en el Perú antes de haberse formado la Comisión de la Verdad y Reconciliación. De esta manera, su nombre comienza a formar parte de las redes de recuperación de la memoria e investigación en la zona andina, sobre todo en Ayacucho, aunque él sea de Lima. Sobre la base de esa preocupación y su experiencia en la capital, su escritura de ficción evidencia el cruzamiento de autobiografía y discurso historiográfico. Su reciente trabajo titulado Persona fue publicado en 2017 por la editorial Fondo de Cultura Económica, lo cual significó otra difusión y distribución para el autor. Sus textos anteriores se conocieron por medio de editoriales más pequeñas o independientes como Interzona, o bien, su famosa obra Los rendidos, sobre el don de perdonar (2015), publicado por el Instituto de Estudios Peruanos.

Sin embargo, el hecho de que uno de sus últimos trabajos irrumpa en el mundo literario con una nueva lógica de circulación y comercialización permite pensar en un intento por visibilizar temas silenciados durante más de diecisiete años, o bien contados desde los discursos más tradicionales como la narrativa. Mark Cox, en el prólogo de su Antología del cuento peruano en los años de violencia, explica que a partir de 1986 se registra la primera narrativa sobre la violencia en coincidencia con el "boom" de la narrativa andina y la edición de textos sobre la guerra interna de distintas casas editoriales de menor envergadura. Paralelamente, observa la ausencia de editoriales de mayor consagración dedicadas a este tema, de ahí la tarea de autoedición de varios autores (Cox, 2000). Esta situación se extendió por varios años, aunque en la actualidad proliferan los libros que abordan el conflicto armado y los criterios editoriales de visibilización de la violencia han captado el interés de casas de edición de diferente entidad y renombre. En ese circuito comercial que muestra el horror, se corre el riesgo de banalizar lo ocurrido. Elizabeth Jelin advierte que existen dos riesgos de la memoria: el peligro del exceso del pasado como ritualización o el silencio instrumentalizado como olvido selectivo (Jelin, 2002: 14). Así, se vuelve imperioso el trabajo con la memoria y la puesta en discurso literario es una forma de elaboración compleja discursiva que busca una reflexión consciente sobre los hechos traumáticos de las últimas décadas.

Trabajar en contra del olvido desde la literatura permite reposicionar las identidades y sujetos en un espacio heterogéneo que no desconoce las pugnas por el sentido del pasado. El concepto de heterogeneidad propuesto por Antonio Cornejo Polar en Escribir en el aire implica reflexionar en torno a los conflictos que no buscan ser resueltos ni cumplir con el legado moderno cuyo mandato es ser homogéneos borrando, negando y ocultando lo disímil (2003: 13). En el caso de Persona, puede observarse desde los primeros paratextos -tapa, ilustraciones, 
disposición textual, subtítulos, entre otros- una voluntad del sujeto por asumir la complejidad de su identidad, empezando por mostrar las contradicciones propias de los discursos hegemónicos respecto de las víctimas y de los deudos. Esas tensiones en convivencia garantizan la resistencia de los otros, en este caso las versiones de parte o contrahegemónicas. En tal sentido, puede pensarse que esta obra opera en contra de las alianzas y negociaciones de esas versiones donde fracasa irremediablemente todo recurso de subjetividad individualizada. No se intenta construir un discurso de identidades sólidas y coherentes, pues fue concebida desde una matriz heterogénea. Su particular estructura hace pensar, en cuanto al tejido de la memoria, en un material lleno de nudos superpuestos que conviven en el gran telar colectivo de los deudos. El diseño de la obra propone una lógica distinta, inesperada para los lectores, oscilante entre el discurso poético, el iconográfico, el ensayístico y autobiográfico. El texto puede ser leído en sus diferentes apartados que remiten a una lógica no tradicional. Cada uno conjuga la voz poética testimonial y el trabajo iconográfico: mapas, fotos, dibujos, tapas de libros, fichas ginecológicas, dibujos y trazos del autor, fragmentos escritos de puño y letra, carteles, entre otros.

Se leen dos posibles lugares constitutivos de la obra: por un lado, las zonas reales, los sitios tangibles, localizables en el mapa del Perú, cuya referencia se vuelve material y visible a los lectores: la zona andina y Lima. Por otro, aquellos imaginarios que dan cuenta de la evocación, de la construcción de la memoria, de un recorrido personal por las zonas donde afloran las huellas traumáticas personales del sujeto poético visibles en marcas y señalamientos como trazos sobre los mapas. Esas dos zonas constituyen formas de construir un tercer lugar: el de la enunciación, el de la voz que se (des)hace y se (re)construye por medio de operaciones de escritura que relatan el horror de la guerra interna.

\section{El lenguaje poético, el lugar de la reconstrucción}

Persona se divide en diez apartados, tres de los cuales remiten directamente a la idea de espacio: "Mapas", "Tierra" y "Muelle". Todo el texto, de hecho, se conduce con una lógica espacial y territorial: se habla del origen, de los residuos, del silencio. Simultáneamente, esos apartados también configuran una cartografía personal: el lugar donde habita la voz literaria -una posible para dar cuenta del horror-que le permite al sujeto poético armar un tejido o mapa de sus recuerdos como sobreviviente de la violencia de la querra. Pero todo el discurso exhibe un afán por cartografíar, como si en esa clave pudiera dar cuenta de un manojo de experiencias juzgadas a simple vista como caóticas, imposibles de nombrar y clasificar. Sumado al material escrito, se observan mapas intervenidos con trazos manuscritos donde se señalan recorridos rememorados con fuerte carga emocional, desde el sitio donde se conocieron sus padres, hasta las señalizaciones de guaridas donde vivían en la clandestinidad. También otros caminos conjeturales acerca de cómo imagina el autor el escape de sus padres e, incluso, de dónde se supone que podrían estar sus restos. Se suman a estos mapas otros en los cuales se intervienen los sitios con preguntas reflexivas del autor, o de la voz, o más bien del trazo verde en el caso de los recorridos de su padre, y rojos en relación con los movimientos de su madre, confluyendo las dos líneas en los encuentros y desencuentros entre ellos. Dentro de esos trazos, aparece el color negro que cuestiona: “ise puede recordar sin marcos de referencia?, ¿cuál es el mapa de una vida?" (Agüero, 2017: 43) haciendo de ese material cartográfico un diario íntimo, el lugar propiamente dicho de sus preguntas existenciales. Esta dinámica de hacer de los lugares concretos y localizables uno atravesado por la subjetividad es una de las líneas más visibles de la obra de este autor (Figuras 1 y 2). 
Los soportes iconográficos remiten tanto a los lugares céntricos como a los periféricos de la ciudad y conjugan las dos dimensiones de la capital peruana. Por un lado, se marcan sitios de tortura, clandestinos, casas allanadas o atentados. Por el otro, las marcas gráficas evidencian otra cara de Lima: no solo como el escenario donde esos hechos se perpetraron, sino el lugar donde puede cuestionarse como víctima, ahora voz en la escritura. Para la voz poética, el mapa debe completarse, intervenirse, con sus conjeturas y recuerdos, pues no son más que elementos de un archivo mayor albergando otros objetos vinculados con los restos de sus padres. Si se tiene en cuenta que la población peruana quedó, durante el conflicto armado, atrapada entre las amenazas de un grupo y otro, puede sostenerse que los mapas nunca más remitieron a un lugar unívoco. Muchas de las víctimas no han sido reconocidas en un registro oficial, incluso hasta la actualidad, y sus restos siguen desperdigados por la geografía andina impunemente. Este detalle es problematizado por el sujeto, quien visibiliza la imposibilidad de muchos deudos de reconocer los cuerpos de sus familiares desaparecidos. Así, se incorpora la ficha odontológica de las víctimas como posible recorrido de búsqueda de reconocimiento, una ficha ginecológica, algunas fotos, las cuales remiten a personas desaparecidas. En este sentido, el autor parece preguntarse por la idea de persona como adelanta en el título, o mejor, por la idea de identidad como una categoría susceptible de ser armada y desarmada por fichas, mapas, objetos, piezas dentales, como forma de construcción desigual, azarosa, clandestina, atropellada por agentes externos. El sujeto se siente -como sostiene en su libro Los rendidos, sobre el don de perdonar-: "objeto de estudio, de opinión, de representación. Es inevitable para las víctimas [...] no pueden detener el uso de una experiencia que, aunque sea suya, no les pertenece ya" (Agüero, 2015: 37). Puede subrayarse, así, el uso de esas vidas desde distintos discursos políticos, historiográficos, antropológicos y que encuentra lugar donde asirse y pensarse: la literatura.

Además del trabajo de mapas y trazados, en los siguientes apartados se muestran una serie de fotos intervenidas de manera tecnológica. En ellas se ve sobre un mismo fondo rural tres posibles familias integradas alternativamente por él y sus padres; en la siguiente, aparecen sólo él y su padre, lo cual da cuenta de la desaparición de su mamá, y así se combinan ausencias hasta llegar a ser él mismo desaparecido de la foto (Figura 3). Ese final donde se lo ve solo opera como punctum barthesiano (Barthes, 1990). Es una presencia punzando el cuerpo social: la materialidad de las víctimas, de los sobrevivientes. Ese es el efecto logrado, como un punctum: perturba y deja marcas sobre la estructura social para los que no los quieren ver y reconocer. Conjeturar una posible foto de la ausencia es conferir visibilidad e importancia a algo o alguien, es poner el énfasis en un nuevo estado, es registrar y evaluar el mundo circundante desde una perspectiva-otra, fuera de foco de la realidad inmediata, o es intervenir en un registro que testimonia la tragedia de las víctimas. Así, el sujeto explora las posibilidades visuales y lingüísticas hasta llegar a quedar en el sitio de la ausencia, pues ahora parecería que no quedó él como sobreviviente, sino que él también desapareció para dejar paso al lenguaje, pues cierra esa combinación de fotos con dos sugerentes preguntas acerca de sus padres, José Manuel Agüero y Silvia Solórzano. Se lee:

¿De qué se arrepiente? José Manuel [...] ¿Debiste amar a una mujer diferente? ¿Una que no alimentará en ti al revolucionario mártir? [...] Silvia, antes de la playa de Chorrillos, de las balas en el pecho, ¿algo que debiste hacer de otro modo? [...] ¿Cómo se corrige la historia? (Agüero, 2017: 104)

Este pasaje concluye la serie de imágenes donde se señala otro modo de cuestionamiento: se cambia de las preguntas personales (a su padre primero y a su madre luego) para esgrimirlas por último con un uso impersonal (“¿Cómo se corrige la historia?") y se pone en evidencia un borramiento del sujeto, lo que sugiere la 
ausencia de identidades. Queda, así, la voz cuestionadora en un escenario en el que parece imposible preguntar e inscribirse a sí mismo: no está en la última foto, no está en el cuestionamiento final. En relación con dicha desfiguración, pensamos ya no en Agüero como un autor, o en un sujeto poético, sino en las marcas del discurso donde se lee un gesto textual. Giorgio Agamben, en "El autor como gesto" (2005), propone la categoría de ausencia/presencia autoral como mueca o gesto posibilitador de la expresión en la medida misma en que instaura en ella un vacío en las marcas del discurso. De ahí que se lea el gesto donde se inscribe un sujeto poético. Se ve en ese vacío, entonces, un lugar posible de enunciación, acaso el único. El poeta, en ese juego dual, en ese gesto, señala un límite o punto de fuga al que no llega nunca la escritura: el material vivido, incluso cuando por medio de imágenes intenta materializarlo, señalarlo, cartografiarlo.

Este cuestionamiento se problematiza a lo largo del libro. En el capítulo "Posnatal", por ejemplo, se lee un poema largo titulado "La otra", donde los sustantivos y verbos sobre el origen refieren a recorridos, trazos espaciales. Inicia el poema: "Debo decir: 'la seguí toda la vida sin que se diera cuenta"' (Agüero, 2017: 111) y esa idea de persecución se disemina a lo largo del texto; el verbo "seguir" se reitera más de siete veces y evidencia una pulsión lingüística muy marcada por el sujeto, pues conjuga la espacialidad, la idea de desplazamiento en busca de su madre además de una idea de insistencia. Aquí el verbo "seguir" remite a no abandonar, a continuar, a permanecer en una actitud de reflexión, reclamo y conmemoración; en definitiva, es lo que problematiza este autor a lo largo de muchas de sus obras. "Seguir", para el sujeto, tiene la forma de sus funciones públicas: como escritor, como activista, como historiador. En este apartado, la noción de lugar cobra otras dimensiones: el cuerpo propio como frontera, es decir hasta dónde el sujeto de enunciación no es más que la copia del cuerpo de su madre, y este, a su vez, un lugar/cuerpo recobrado por la memoria: “¿en qué momento invisible su esquina dejaba de ser ella y pasaba/a ser/ el ambiente, el clima, la tierra, la basura?" (Agüero, 2017: 112). Entonces ese cuerpo de la madre descripto es el lugar de los restos, pero también una zona inasible que debe perseguir.

Hay en el trabajo sobre la identidad y la memoria un cuestionamiento que rebasa los límites de lo personal. En el reconocimiento que el sujeto poético hace de su identidad -en relación con los restos familiares- está el reconocimiento de la comunidad, de los deudos, del cuerpo social. En tal sentido, el pasado excede la temporalidad y la biografía de un sujeto, y en esa coyuntura se encuentra el espacio vivo de la cultura actual, la arquitectura colectiva de un pasado dentro del postconflicto. La historia y la memoria son los referentes de una escritura como espacio de sentido social. En esa relación, el lenguaje como material poético intenta impedir el anquilosamiento y promover lo que Todorov llama memoria ejemplar. Es decir, evitar la recuperación del pasado cuya utilización evidencie el abuso de intereses políticos de ciertos grupos y trabajar para conservar ya no una memoria literal, intransitiva, como hecho en sí mismo, sino ejemplar, como modelo de comprensión (Todorov, 2000). No serviría, pues, referir una experiencia solo por el hecho de singularizarse dentro del pasado, sino como modelo que permita comprender nuevas situaciones, generalizando, extrayendo de él un ejemplo o lección provechosos. De modo tal que la palabra poética, la cartografía de las zonas violentadas por el terror, los restos constituyen marcas posibles donde leer y trabajar la memoria colectiva.

\section{La memoria, el asilo de los restos de la comunidad}

Con una similar lógica escrituraria, el sujeto propone el apartado "Épica". En él se lee la relación de los cuerpos/restos por momentos devenidos semilla -acaso en la mirada más esperanzadora- y los restos podridos, no identificados y anónimos que circundan 
lugares transitados por todos, como el penal de "El Frontón" donde murió su padre. En este capítulo se cuestiona, por un lado, su condición de víctima, pero también la posición de su escritura, de su voz indicadora del horror. De esta forma, inviste una posición de sujeto poético enunciado como aquel a quien le toca "ocupar el lugar como hijo de mártir" (Agüero, 2017: 123). Se lee así otra operatoria en torno a la idea de espacio no como sitio sino como rol social delimitado. Simbólicamente, este sujeto coopera como actor social en el andamiaje construido por fuera de su voluntad: es el hijo de un agente activo de la guerra. La voz poética parece manifestar falta de interés por teatralizar la escena del trauma familiar requerido por parte de la sociedad del postconflicto. Sin embargo, cabe reparar en esa última cita -"ocupar el lugar como hijo de mártir"- el uso del nexo comparativo "como", que indica carácter ficticio o de simulación de muchas de las víctimas. De esta manera, el autor deja de manifiesto su posición frente a esos roles rígidos y preestablecidos que lo señalan alternativamente como "víctima" o "hijo de terruco", sujetos a quienes no se les permite el duelo y el dolor (Agüero, 2015). Para él, la sociedad destina a los hijos de estos agentes activos de la querra posiciones sociales fijas y determinadas en el escenario sociopolítico y cultural. El escritor asume posturas variadas y a veces antagónicas a lo largo de sus trabajos. Esta situación no opera como una incongruencia, sino más bien evidencia una imposibilidad de asirse en lugares predeterminados ideológicamente por uno u otro sector. En esa oscilación se leen reclamos personales, reivindicaciones, hostigamiento contra aquellos que quieren, en términos políticos, manipular los cuerpos muertos y acomodar a los sobrevivientes.

También la isla de "El Frontón", lugar donde estuvo preso y finalmente murió su padre, se vuelve un sitio difícil de visitar con el cuerpo y con el lenguaje: "la isla sigue siendo un tabú. Y el modo en que hablamos de ella, un gran eufemismo nacional" (Agüero, 2017: 125). En varios pasajes, el sujeto explicita que ese sitio es la muerte, el silencio, los asesinatos extrajudiciales (como el de su padre), "el Callao, el muelle, la isla. Y el mar. Esa otra forma de sangre" (Agüero, 2017: 126). Esta idea atraviesa muchos apartados y se condensa en el capítulo "Traición", pues ahí se cuestionan los límites de ese tercer lugar, el del lenguaje literario.

En dicho apartado, el sujeto problematiza el valor del arte para dar cuenta de los restos, de la memoria: "No hay que ir muy lejos para ver esta exhibición. Los restos sin importancia de unos terroristas masacrados están en cajas en la Fiscalía. / Esperando su poeta" (Agüero, 2017: 56). Así, interpreta con distintas voces poéticas y fotos una muestra de arte dedicada a las víctimas de la guerra, como reliquias del mal. En este sentido se combinan distintas actitudes críticas respecto de las exhibiciones tales como las del Museo de la Dirección Nacional, la muestra del artista Giancarlo Scaglia o la estética del Lugar de la memoria. En ese recorrido, por sus observaciones sobre dichas muestras, el sujeto poético se constituye como un observador crítico de esos materiales pictóricos explicativos del horror, narra: "las fotos más usadas, las que más nos conmueven, no pertenecen al lugar donde ocurrieron el motín y la masacre de los presos del El Frontón" (Agüero, 2017: 148) y luego agrega: "La zona donde los presos fueron masacrados [...] la zona de mis recuerdos, no se presta para la representación ni para la buena intención. Porque no hay nada. Ha sido objeto de una sistemática intención de convertirla en nada" (Agüero, 2017: 150). De esta manera, esgrime una opinión no solo estética sino también ética: mostrar que para el sujeto tiene la invalidez de todo acto de enunciación, se vuelve irremediablemente en contra de la lógica que lo engendró evaporando toda posibilidad de sentido.

El recorrido por este capítulo demuestra la denuncia, la victimización, hasta la problematización artística, para finalizar con unos versos sobre una exhibición del muro del penal de "El Frontón", junto con la foto de un ex hijo en un ex pabellón: "No hubiera querido ver ese pedazo de muro de la isla donde mataron a tantos conocidos, 
donde mataron a mi padre, exhibido así [...] la gente que está atada a ellos, ¿tiene algo que ver en este mercado?" (Agüero, 2017: 54). Se evidencia un cuestionamiento que excede los límites históricos en aras de pensar la relación memoria/mercado. No obstante, cierra el apartado con la imagen dibujada de un niño, quien deja trazos a sus espaldas, los cuales podrían dar cuenta de un recorrido. El niño también porta ladrillos en la mano (Figura 4). Por lo cual puede observarse una condensación en ese pasaje icónico y verbal, como se lee en la cita, el espacio en esas tres dimensiones antes señaladas (real: la cárcel, subjetivo: el espacio en forma de recuerdo, y simbólico: el arte como espacio posible para contar esa memoria) para construir un mensaje otro: el del silencio, como precisamente llama a su penúltimo apartado de Persona. Entonces, la figura del niño constructor con ladrillos, la problematización en torno al mercado de la memoria y lo que queda (silenciado, olvidado) se vuelven los ejes finales de su texto. Sobre el cierre aparece una coda, un apéndice residual: el apartado "Residuos". En este último intento de identificación, el sujeto poético es un resto que reflexiona sobre su carácter de tal. Sus últimas imágenes y palabras se ven acompañadas de un trazo elemental que muestra una figura de alambre humana, es decir, un resto que asume una voz irónica respecto de los temas problematizados en su libro: la memoria, la condición de víctimas y deudos, su identidad como hijo de senderistas, la escritura mediada por su labor como historiador, la tensa relación arte/memoria en el sistema simbólico del mercado de la violencia:

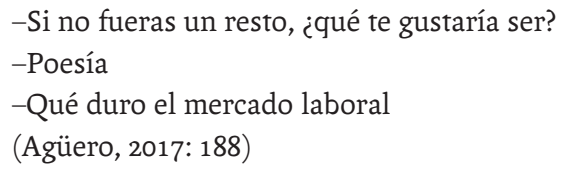

La cita evidencia no solo una voz que pasa de la victimización a la crítica, del cuestionamiento a la ironía, sino también una tensión respecto de los problemas más visibles en los trabajos de memoria: qué se hace con esa memoria evocada. En tal sentido es útil pensar en la distinción que propone Jelin cuando diferencia entre el reconocimiento como la identificación de un hecho referido al pasado y la evocación que implicaría la evaluación de lo reconocido de manera más activa por parte del sujeto. Una evaluación que implicaría un trabajo de internalización (2002: 23). De este modo, las fichas, las fotos, los materiales de archivo de muestras y museos deben garantizar las evocaciones por medio de sujetos activos, pero también, que puedan ser cuestionados o problematizados dentro del mercado simbólico y dentro de las pugnas políticas por la reconstrucción del pasado.

\section{Sobre el final, el silencio}

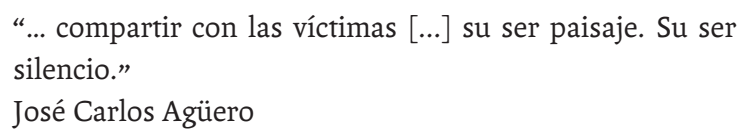

Sobre el final de Persona parece quedar el "Silencio", evidencia de una apuesta nueva del sujeto, quien no busca garantizar en el lenguaje o en el arte lo que se intenta decir o recordar. Parecería que, en el silencio, en el hueco residual de lo nombrado, en lo no dicho, se cifra una posibilidad de dar cuenta del horror, pero no desde la negación. Señala precisamente que en ese punto de fuga queda acaso lo material, los espacios como testigos callados. En este sentido, todo lo acallado en documentos oficiales aflora en la literatura. Las memorias sobre la guerra interna oscilaron entre las oficiales como aquella de la CVR o las emanadas de otros organismos públicos como las surgidas de las Fuerzas Armadas, consideradas parciales. Asimismo, las "versiones de parte" (Agüero, Pease, Portugal, Uccelli, 2017: 23) junto con aquellas en las que se observa 
un uso capcioso de la pacificación, sumadas a las historias marginales, pueden leerse como contracara de las historias militares. En este intento por dar cuenta de las vivencias traumáticas se terminó acallando el horror.

Como sostiene Dominick LaCapra, tiene valor el hecho de volver a vivir el trauma como conmemoración dolorosa en tanto trauma fundacional (LaCapra, 2005). El trauma funciona como sustento de la identidad de muchos peruanos. En su afán de reconstrucción, Agüero comparte no sólo su filiación con la guerra, sino una identidad generacional postconflicto sujeta al terror desde un presente categórico que obliga a hacer memoria y evitar el silenciamiento. Así, el sujeto de sus poemas, descentrado, pone en acto sus angustias, dudas y señalamientos y siembra prácticas significativas en sus lectores con quienes puede compartir su situación traumática como víctima. No hace más que preguntarse(nos) hasta qué punto las vivencias traumáticas pueden problematizarse desde la escritura, o mejor, problematizan la escritura y la representación.

Agüero construye en su escritura un espacio de tensión entre el silencio y la experiencia, entre las versiones acalladas y las oficiales, como él mismo declara: "esta es una apología del silencio. No basta rastrear las huellas. Estas, a su modo, agregan gritos. Pueblan el mundo, lo oscurecen al hacerlo multitud ilegible de heridas" (Agüero, 2017: 173). Como se observa en la cita, no hay sujeto, pues ya no importa quién habla: José Carlos, la voz poética, la víctima, el lenguaje despojado de toda subjetivación, porque la memoria, parece decir el autor, no es industria, no es provocación, es trampa-como el lenguaje- de la que el hombre no puede deshacerse. 


\section{Bibliografía}

》 Agamben, G. (2005). “El autor como gesto”. En Profanaciones (pp. 78-94). Buenos Aires: Adriana Hidalgo.

" Agüero, J. C. (2015). Los rendidos. Sobre el don de perdonar. Lima: IPE.

»Agüero, J. C. (2017). Persona. Lima: Fondo de Cultura Económica.

» Agüero, J. C.; Pease, M. A.; Portugal, T. y Uccelli, F. (2017). “Introducción”. En Atravesar el silencio. Memorias sobre el conflicto armado interno y su tratamiento en la escuela. Lima: Instituto de Estudios Peruanos.

» Barthes, R. (1990). La cámara lúcida. Barcelona: Paidós.

»Cornejo Polar, A. (2003). Escribir en el aire. Lima: CELACP.

»Cox, M. (2000). “Prólogo" a El cuento peruano en los años de violencia. Lima: Editorial San Marcos.

" Jelin, E. (2002). Los trabajos de la memoria. Madrid: Siglo XXI.

"LaCapra, D. (2005). Escribir la historia, escribir el trauma. Buenos Aires: Nueva Visión.

»Todorov, T. (2000). Los abusos de la memoria. Barcelona: Paidós. 


\section{Apéndice}
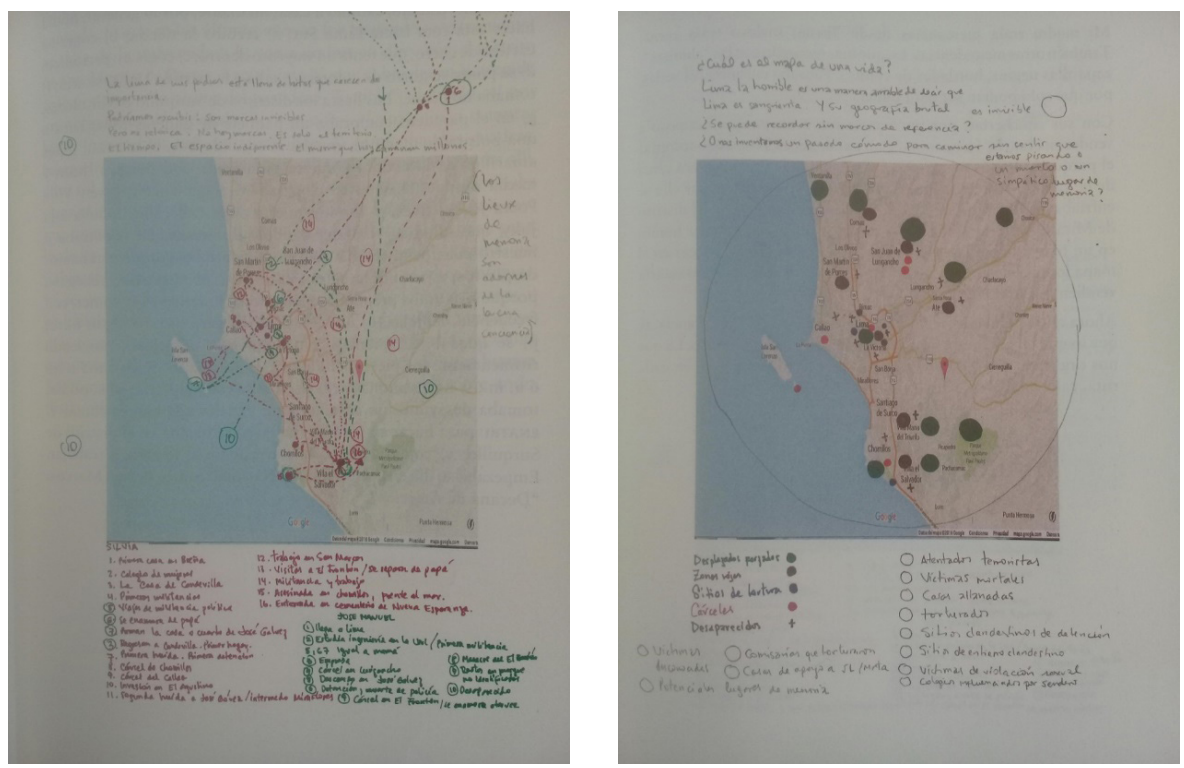

Figuras 1 y 2. Mapas intervenidos por el autor
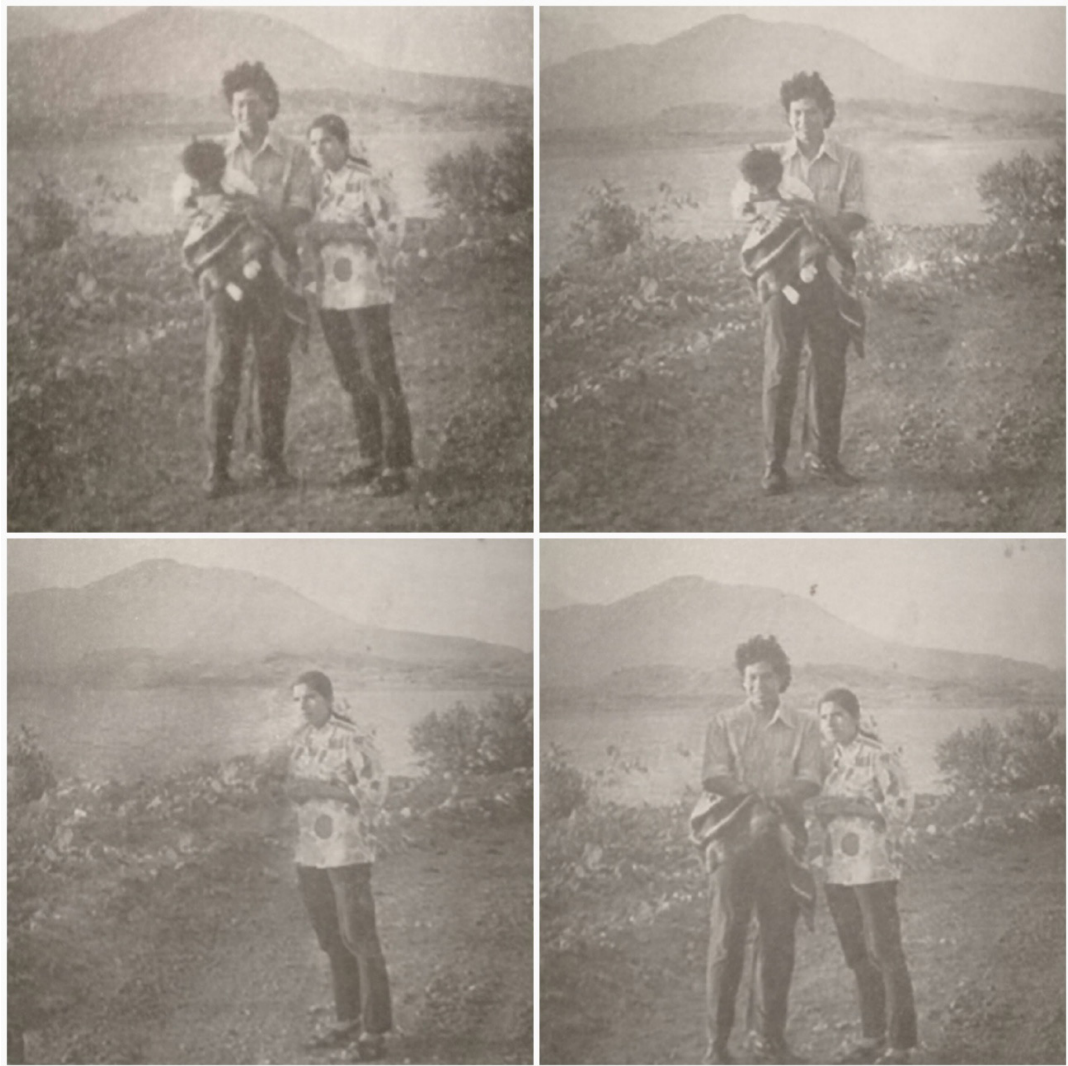

Figura 3. Combinación de fotos sobre un mismo marco mostrando distintos sujetos desaparecidos dentro del mismo núcleo familiar (el collage es mío) 


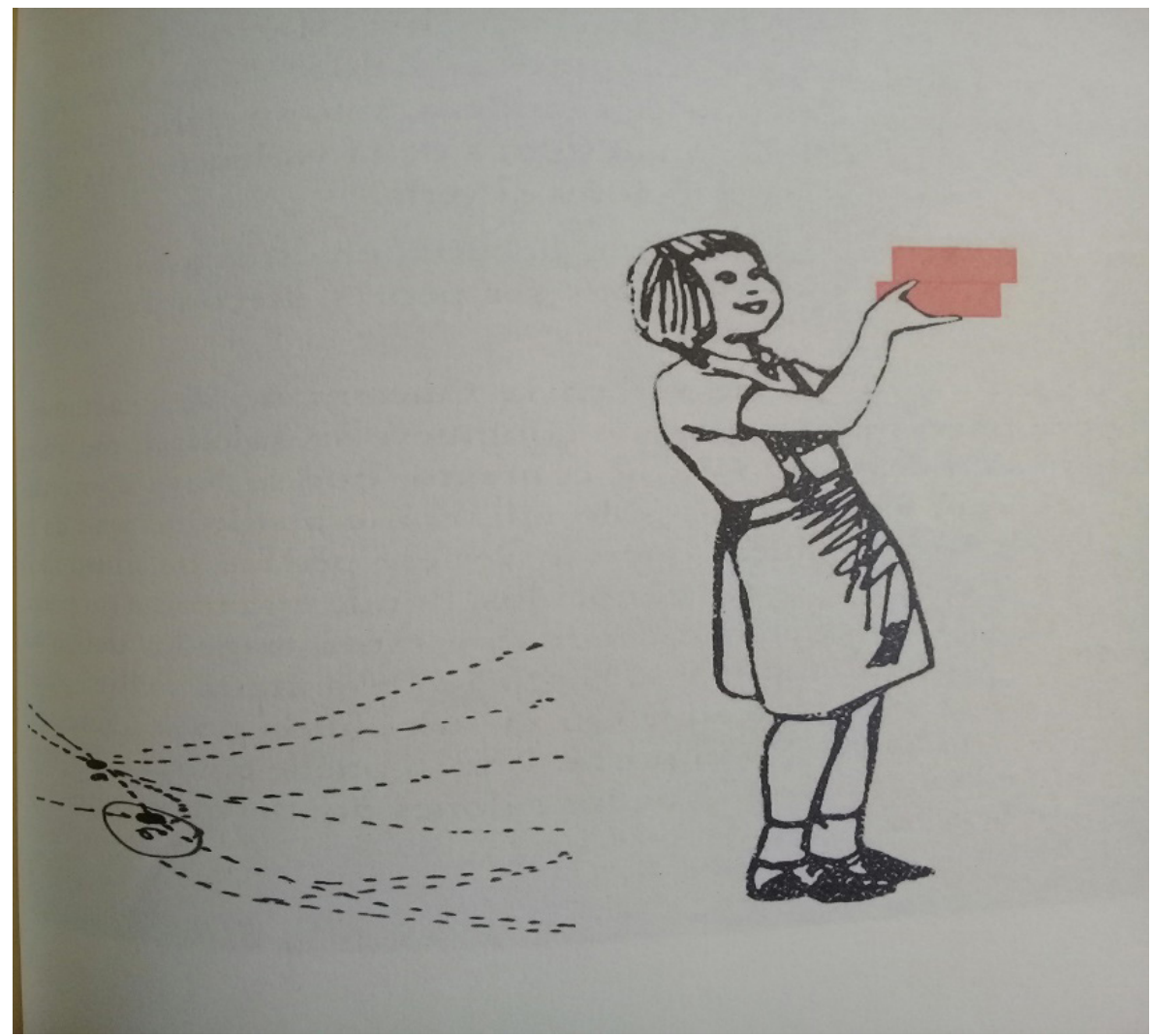

Figura 4. Dibujo del capítulo “Traición” y reformado para el cierre del apartado "Residuos" 